\title{
Turismo Gourmand: $O$ luxo e a gastronomia como vetores para o apetite de viajar
}

\section{Gourmand Tourism: The luxury and gastronomy as vectors for the hunger of traveling}

\author{
Ewerton Reubens Coelho Costa (COSTA, E. R. C.) ${ }^{*}$
}

RESUMO - Este artigo tem como foco identificar pontos importantes das ligações entre o luxo e o turismo, e como eles forjam-se num contexto evolutivo onde a alta gastronomia se configura como elemento-chave para dar vida ao turismo gourmand. $\mathrm{O}$ trabalho foi desenvolvido com base na revisão bibliográfica. Dentre os principais resultados, confirma-se que a presença do luxo na gastronomia vem desde a antiguidade; que o conhecimento sobre alimentos de luxo foram disseminados a partir de viagens - elemento característico da atividade turística; e, que a gastronomia combinada com ingrediente de luxo tem o poder de atrair visitantes, criando assim o segmento turístico gourmand.

Palavras-chave: Turismo Gourmand; Luxo; Gastronomia.

ABSTRACT - This article focus on identifying important connections between luxury and tourism, and how they are forged in an evolutionary context where the high gastronomy is configured as a key element to give birth to gourmand tourism. This paper was developed based on literature review. Among the main results, it is confirmed that the presence of luxury in gastronomy comes from antiquity, that the knowledge of luxury foods were disseminated throughout trips - a characteristic element of tourism activity, and, that the gastronomy combined with luxury has the power to attract visitors, thus creating the gourmand tourism.

Key words: Gourmand Tourism; Luxury; Gastronomy.

\footnotetext{
* Graduação Tecnológica em Gestão de Turismo pelo Centro Federal de Educação Tecnológica do Ceará. Mestrando em Educação Brasileira pela Universidade Federal do Ceará - UFC. Formador de Gestores das Políticas Públicas do Turismo pelo Ministério de Turismo - MTUR e Universidade Federal de Santa Catarina - UFSC. Endereço: Rua José Adail dos Santos, 70, ap. 407 (Presidente Kennedy). CEP: 60355631. Fortaleza - Ceará (Brasil). Telefone: (85) 9929-2498. E-mail: ewertonreubens@ @otmail.com
} 


\section{INTRODUÇÃO}

O fenômeno do turismo faz com que pesquisadores e estudiosos se debrucem sobre a realidade na busca por teorias que possam explicar melhor o que ele significa. A segmentação do mercado turístico serve como exemplo para demonstrar as mudanças da sociedade (demanda turística) de acordo com o período histórico. É através da segmentação que se pode conceituar as tipologias do turismo observando as necessidades de cada nicho e, assim, esboçar o perfil diferenciado de cada tipo de turista.

O presente artigo apóia-se num estudo bibliográfico que visa refletir sobre a relação entre turismo e a alta gastronomia (considerada como luxo), na busca por um maior entendimento sobre o que vem a ser o turismo gourmand (nicho onde estão reunidos o turismo de luxo e o turismo gastronômico) e suas formas presentes na atividade turística.

Desde já, entretanto, torna-se importante esclarecer que o tema a ser desenvolvido por esse artigo vem para dar continuidade às pesquisas do autor, que nos últimos anos vem dedicando-se aos estudos culturais, com ênfase na gastronomia - seus afins e particularidades. Antes porém, de adentrar no tema central deste trabalho, faz-se necessário tecer algumas considerações sobre a presença do luxo - na gastronomia e no turismo.

O conceito de necessidade versus luxo é complexo, porque eles são claramente termos relativos. Berry (1994, p. 12) conclui que o luxo deve ser visto como "objetos de desejo". Geralmente associado com o prazer físico ou sensorial, através de decisões intencionais, privilegiadas pelo poder financeiro, que permite uma escolha caracterizada por um refinamento qualitativo; como segue o exemplo: estar com fome e precisando de pão para saciar esta fome, mas desejando pão fresco, feito a partir de farinha integral orgânica; ou, estar frio e precisando de roupas, mas desejando um casaco de cashmere em vez de casaco qualquer.

A ostentação do luxo é um ato cultural e está presente no mundo desde os mais remotos tempos. Lipovetsky e Roux (2005, p. 27) afirmam que através da religiosidade pode-se observar as "condições da emergência do luxo primeiro". 
E se for observado bem o contexto, as viagens e o que hoje se entende como turismo e hospitalidade acaba se entrelaçando com a presença do luxo, já que as primeiras ostentações estariam ligadas aos rituais religiosos, onde as sociedades antigas ofereciam danças, comidas mais requintadas, todos os tipos de mimos não costumeiros para agradar aos seus deuses. E os visitantes dos santuários precisavam, na maioria das vezes, se deslocar e se restaurar (comer, beber e se acomodar) em algum lugar. Porém, o luxo da comida ficava restrito aos poderosos e aos altares de adoração:

Honrar os deuses é garantir-lhes uma vida luxuosa, preparar-lhes banquetes festivos, refeições servidas em baixelas de ouro e prata, fazer-lhes oferendas de jóias preciosas e de vestimentas de aparatos. (LIPOVETSKY; ROUX, 2005, p. 30).

Talvez seja por causa da religiosidade que alguns autores colocam a origem etimológica da palavra luxo com o significado de "luz". Pois era exatamente isso que os devotos buscavam nos santuários e templos: luz sagrada, orientação para trilhar seus caminhos. E quem possui um bom dicionário de etimologia vai perceber que o termo luxo é derivado do latim luxus (sendo este adjetivo e substantivo de uma só vez) tendo sido gerado a partir de vocábulos agrícolas onde significou inicialmente "o fato de crescer de lado", depois "crescer em excesso" para então significar "excesso em geral” e somente vir a ser "luxo" no século XVII (LIPOVETSKY; ROUX, 2005, p. 115 ).

Foi justamente nos templos onde o luxo começou a se fazer presente: fosse pelos materiais nobres para a construção das edificações sagradas ou nos presentes ofertados aos deuses; ou ainda, pela ostentação e opulência das celebrações e banquetes ocorridos nas datas festivas e afins, realizadas naqueles locais sagrados.

$\mathrm{O}$ uso dos metais e das pedras preciosas como fonte de riqueza e poder, aliados às hierarquias governamentais adotadas pelas sociedades antigas acabou tirando o sentido sacro do luxo, tornando-o algo mais mundano e materialista, exclusividade que somente os nobres e os nascidos em famílias abastadas poderiam ostentar.

Na escala da longuíssima duração, não há duvida de que o aparecimento do Estado e das sociedades divididas em classes constitui uma das rupturas mais importantes da história do luxo. Quando se impôs a separação entre senhores e súditos, nobres e plebeus, ricos e humildes, o luxo não mais coincidiu com os fenômenos de circulação - distribuição - desentesouramento das riquezas, mas com nova lógica de acumulação, centralização e hierarquização. Este novo momento histórico é o que vê surgir os ricos mobiliários funerários, as 
arquiteturas e esculturas grandiosas, os palácios e as cortes, as esplendidas decorações e outras suntuosidades encarregadas de traduzir na pompa o poder superior das soberanias, celestes ou terrestres. (LIPOVETSKY; ROUX, 2005, p. 28).

Com o crescimento e desenvolvimento das sociedades o luxo estava presente, nas suas mais variadas formas, e poderia ser entendido em todos os continentes, variando de acordo com os interesses e valores das populações. Hoje o mercado de luxo é uma fatia da economia mundial que já ultrapassa os 400 bilhões de dólares (GUIA DA SEMANA, 2011). Dentro deste mercado encontram-se alimentos de luxo, alvo das observações do tópico a seguir.

\section{O LUXO NA ALIMENTAÇÃO}

Quando o homem dominou o fogo há 500.000 anos as refeições deixaram de ser somente cruas para serem cozidas e/ou assadas. Surgiu então o que Flandrin e Montanari (1998, p. 22) denominam por "humanização dos comportamentos alimentares" - episódio que distinguiria os homens dos animais através das funções sociais da alimentação. O homem então deixa de ser sedentário, inicia a agricultura, mantém um sistema de caça e passa a apresentar hábitos de convivência à mesa.

E se existem elos entre a cultura e o homem, certamente, o mais importante deles é a alimentação. Para Carneiro (2003, p. 1) a alimentação "é, após a respiração e a ingestão de água, a mais básica das necessidades humanas". O ato do comer além de oferecer todos os elementos que o corpo humano precisa nutre também a alma e pode, ainda, até instituir contato com o passado ou com os deuses. Esta maneira abrangente de pensar a alimentação trata-se da gastronomia. Cuja definição clássica é apresentada por Costa (2011, p. 119):

A gastronomia (do grego antigo $\gamma \alpha \sigma \tau \rho o v o \mu i ́ \alpha ; \gamma \alpha \sigma \tau \rho o ́ \varsigma$ ["estômago"] e vouía ["lei"/"conhecimento"], literalmente as leis do estomago) é a área do conhecimento humano que envolve a culinária, as bebidas, os ingredientes (especiarias, temperos, farinhas, queijos, etc.) usados nos preparos das refeições, os utensílios que são exigidos no preparo dos pratos e todas as características a elas associados. Entretanto não se deve confundir a gastronomia com a culinária (arte puramente de confecção dos alimentos), nem com a nutrição e a dietética (que examinam a alimentação do ponto de vista da saúde e da medicina). 
Esta definição comunga com o entendimento de Brillat Savarin (1995) sobre o tema, alvo de seu livro "A Fisiologia do Gosto", onde o autor apresenta estudos sobre a alimentação e o que ele compreende por "metafísica dos costumes", para construir uma filosofia ou uma ciência da gastronomia. Dentre as justificativas encontradas para a elaboração do seu "tratado gastronômico" Savarin (1995, p. 15) utiliza-se de duas frases bem conhecidas pelos estudantes e pesquisadores das ciências que utilizam a gastronomia como foco: "O Universo nada significa sem a vida, e tudo o que vive come"; e "Os animais se repastam; o homem come; somente o homem de espírito sabe comer".

Sendo assim a "arte culinária" é a maneira pela qual o homem demonstra a sua “capacidade de por em prática uma ideia” (BUARQUE DE HOLANDA, 1999, p. 204), demonstrando seus dotes na elaboração e exposição dos alimentos, segundo normas gastronômicas ou dietéticas, exercitando habilidades para despertar sensações (concitando ao uso) e produzir reações (conduzindo à gratificação).

Com esse pressuposto se pode afirmar que as condições históricas, geográficas, climáticas, sociais, econômicas, técnicas e culturais têm ligações diretas na alimentação de um povo. E assim pode-se divagar numa infinidade de receitas com ingredientes (temperos, aromas, cores e sabores) diversificados; onde, às vezes, os pratos são ricas celebrações de abundância e outras vezes simples, pela escassez dos ingredientes; algumas vezes as refeições podem vir cobertas por mitos e salpicadas com tabus; outras vezes a comida surge, exclusivamente, para se tornar obra de arte.

Para Fischler (2001, p. 20) o homem se nutre também de imaginário; podendo ainda valorar a quantidade de nutrientes de um alimento e até incluir um valor simbólico para eles. É através do simbolismo, repassado pela cultura de cada povo, que se tem como se basear quanto à existência de alimentos do bem (aqueles que trazem benefícios para a saúde) e do mal (os que trazem malefícios), para que possa fazer a escolha do que ingerir durante as refeições.

Baseando-se em Savarin (1995), percebe-se que a gastronomia é um ato de avaliação individual através do qual dá-se preferência às comidas que mais agradam ao paladar em detrimento daquelas que não são agradáveis. E para melhor exemplificar a alimentação através do imaginário e pelo simbolismo pode-se citar a poção das bruxas 
de Machbeth (SHAKESPEARE, 2002), onde alimentos repugnantes são utilizados nos preparos e transmitem o mal (mal-estar, medo, aversão etc.):

\begin{abstract}
BRUXA - Atirai no caldeirão entranhas em podridão. Os sapos das pedras frias que durante trinta e um dias suaram seu bom bocado, jogai no pote encantado.

TODAS - Mais dores para a barrela. Mais fogo para a panela.

SEGUNDA BRUXA - Lombo de cobra novinha atirai no pote asinha, pé de sapo e lagartixa, de cão a língua que espicha, pelos brandos de morcego, asa de bufo-sossego, de lagarto a perna fina, acúleo de colubrina jogai na sopa do mal nesta mistura infernal.

TODAS - Mais dores para a barrela, mais fogo para a panela.

TERCEIRA BRUXA - Três escamas de dragão, com bucho de tubarão que os mareantes intimida; cicuta à noite colhida, bofes de um judeu malvado, ramo de teixo tirado em noite de muito escuro; beiço de tártaro, o duro nariz de turco, o dedinho de uma criança sem linho que matado a mãe houvesse sem dizer nenhuma prece. Deixai bem forte a mistura; juntai do tigre a fressura, porque nosso caldeirão tenha caldo em profusão.

TODAS - Mais dores para a barrela, mais fogo para a panela.

SEGUNDA BRUXA - Esfriai com sangue de mico que o encanto ficará rico. (SHAKESPEARE, 2002, p. 30-31).
\end{abstract}

Assim as poções de bruxa são produtos do imaginário, da cultura, e são compreendidas através do simbolismo como alimentos do mal. E estes simbolismos também podem mudar seu significado de acordo com a época e as circunstâncias sociais: é comum nos lugares assolados pela fome e pela miséria, encontrar alguém comendo restos do lixo e animais repulsivos como ratos, lagartos e cobras - alimentos antes tidos como "do mal" passam a ser "do bem", pois acabam sendo o único meio para a sobrevivência.

Se a comida é tratada como um código, as mensagens que ela codifica serão encontradas no padrão das relações sociais que estão sendo expressas. A mensagem trata de diferentes graus de hierarquia de inclusão e exclusão, de fronteiras e transações através de fronteiras. (DOUGLAS, 1972, p. 61).

Deste modo, o luxo na gastronomia nada mais é, senão, uma supervalorização simbólica dos alimentos. Fato que teve significado compreendido e absorvido com a diferenciação e o status conferido a comida, ainda nas sociedades da antiguidade. $\mathrm{O}$ simbolismo na alimentação acabou gerando uma cozinha cheia de "valores".

Com o desenvolvimento das civilizações e o aparecimento de hierarquias (pobre, rico, nobre, plebeu etc.) a alimentação passa a ser distinta para cada camada social. Valbelle (1990, p. 111) e Casson (2001, p. 45) fazem referências a este assunto trazendo 
da Literatura Sapiencial egípcia, as Instruções de Ptahhotep, Vizir do Faraó Issi, datadas cerca de 2.400 a. C., cujo conteúdo de seus textos louvava os méritos de uma mesa e o cerimonial, ou à correta disposição dos alimentos nos banquetes. Bresciani (1998) vai além e demonstra através do Papiro Anastasy IV a uma ementa preparada para um Faraó da XIX Dinastia e para o seu numeroso séquito durante uma viagem oficial:

10.000 biscoitos (ibiscet), 1.200 pães asiáticos, 100 cestos de carne seca, 300 peças de carne (deghit), 250 punhados de entranhas de boi, 10 gansos com penas, 40 patos cozidos, 70 carneiros, 12 espécies de peixe, codornizes gordas, pombos de Verão, 60 medidas de leite, 90 medidas de nata, 30 potes de sementes e de polpa de alfarroba, 100 pés de salada, 50 cachos de uvas correntes e 1000 cachos de uvas do oásis, 300 réstias de figos, 50 potes de mel de favos, 50 potes de pepino, 60 cestos de bolbos de alho-porro (120 punhados), óleo da região (óleo de sésamo e óleo doce de Moringa), óleo importado (óleo de Chipre, óleo do país dos Hititas, óleo-nekefeter da Babilónia, óleo da região de Amor, óleo da Síria, óleo de Naharina), bebida paur (para os servos), cerveja síria e vinho da Palestina. (BRESCIANI, 1998, p. 54).

Observando a lista acima se pode concluir que a nobreza egípcia já possuía refeições equilibradas e variadas. Provavelmente pelo poder da sua agricultura realizada nos campos férteis à beira do Nilo.

Uma máxima antiga afirma que Deus criou os alimentos e o Diabo os condimentos. Este comentário leva ao primeiro ponto de partida para o uso do luxo inicial à mesa (a condimentação), onde se estabelece uma diferença fundamental na forma de como se encara o conceito de comida de luxo: por um lado está a comida como manutenção da vida (alimentos não condimentados) e por outro como prazer (alimentos condimentados).

Quando se pensa em comida de luxo é corriqueiro fazer ligações entre as modas culinárias geradas pela influência de personagens históricos. Um exemplo para esta afirmativa vem da França, onde, a Rainha Catarina de Médicis ajudou a difundir a moda dos licores - depois da introdução do açúcar na Europa.

É bem verdade que a intensificação do luxo para a gastronomia tenha alavancado seu status a partir da inclusão de certos alimentos, inicialmente na mesa da nobreza e aristocracia, como o açúcar, o café, o chá e o cacau. Tais alimentos eram símbolos de luxo porque custavam caro e quem os possuía assegurava uma clara divisão entre nobreza e plebe, ricos e pobres, senhores e escravos. Fato que mudou hábitos alimentares e ajudou no crescimento do capitalismo. 
O luxo ligado à comida nasce na Itália durante os séculos XV e XVI, quando se assiste à formação da arte culinária, juntamente com as outras artes. Antes só existia o devorar. Agora, refina-se esse prazer e substitui-se a quantidade pela qualidade. Esse luxo passa para França em finais do século XVI. (COSTA, 2010, apud SOMBART, 1990, p. 201) ${ }^{1}$.

Mas deve-se observar que já existia a presença do luxo na gastronomia da antiguidade. De certo que Costa (2010) refere-se, em seu texto, ao luxo adquirido por técnicas recentes de preparo dos alimentos. Porém não se pode negar a importância dos primeiros luxos advindos da alimentação de antigas civilizações: os condimentos.

Bresciani (1998, p. 59-60) afirma que certos tipos de condimentos já eram utilizados pelos egípcios para as refeições dos mais abastados, e cita dentre eles: o mel, escuro ou claro, produzido pelas abelhas nos extensos campos do delta e conservado em vasilhas, cujas rolhas eram seladas com cera; o sal (utilizado de dois tipos: o sal do Norte e o sal vermelho); o zimbro, o anis, os coentros, os cominhos, o funcho, o fenugreco com cheiro de açafrão, semelhante ao atual caril, e as sementes de papoula dormideira.

De acordo com Cimmino (2002, p. 319), o Egito do Império Novo já conhecia quarenta tipos diferentes de pães: pequenos, ovais, triangulares, redondos, cônicos etc., tendo variações de ingredientes no seu preparo como: mel, leite, manteiga, ovos e, até, figos. Nota-se, com isso que, já existiam técnicas bastante elaboradas para o preparo destes e de outros alimentos, para àquela época - fato que já poderia ser colocado como presença de uma cozinha egípcia gourmand, onde as variedades de pães; preparos de peixes, carnes e aves condimentadas eram servidos nas ocasiões especiais para pessoas "especiais" com ostentação.

Além dos egípcios, ainda pode-se destacar a Grécia e a Roma antiga como nações que utilizaram o luxo na gastronomia. Porém a conquista romana do território grego (146 a.C.) intensificou o uso dos hábitos e dos requintes orientais acolhidos pela civilização grega, em Roma. A documentação histórico-literária mostra exatamente isso, pois existem textos privilegiando os banquetes da elite romana, tais como Apicius (1987, 1988, 1990); Dioscórides (2000); Plínio, o Velho (1991); Diodoro (1984); Blanc e Nercessian (1992); Amigues e Théophraste (1998); André (1981); Castro (1997),

${ }^{1}$ COSTA, E. R. C. O Barão contando história I: O luxo do chocolate quente! [Artigo on line]. Publicado em 16 de setembro de $2010 . \quad$ Disponível em: $<$ http://confrariadobaraodegourmandise.blogspot.com /2010/09/o-barao-contando-historia-i-o-luxodo_16.html>. Acesso em: 06/05/2011. 
autores que acabavam descrevendo detalhadamente a maneira como eram o preparo, o aspecto e, principalmente, o sabor que atribuíam a alguns alimentos.

Roma adotou da Grécia o luxo gastronômico com a introdução de hábitos à mesa e a importação de ingredientes e de novas práticas alimentares. E isso se exprime perfeitamente na mesa romana com a importância dos molhos, sobretudo o garum e dos vinhos condimentados.

Curtis (1983) apresenta o garum como um molho de luxo feito à base de peixe, sal e ervas aromáticas; que ainda levava na sua composição sangue, vísceras e outras partes do atum e da cavala, misturados com peixes pequenos, crustáceos e moluscos esmagados; tudo era misturado deixado em salmoura e ao sol durante dois meses ou então esquentado no fogo para ser guardado em ânforas, quando não utilizado.

Os molhos romanos eram feitos para cozinhar os alimentos ou mesmo para ser servido como cobertura destes. Tinham como característica principal: a mistura do doce e do ácido com poucas quantidades de azeite. O uso dos condimentos (ervas aromáticas, especiarias, vinho e o garum) era um meio fácil de neutralizar o odor exalado pela má conservação de carnes e peixes, e o sabor alterado e o perfume dos condimentos atraia o paladar romano.

Nos textos sobre Apicius (1987, 1988, 1990) se encontram as recomendações dele quanto ao uso de ingredientes de luxo (pela importação) para o preparo de molhos: pimenta da Índia (demorava onze meses para chegar a Roma), tâmaras de Jericó, coentros e cássia da China, cebolas galesas, açúcar da Pérsia, canela do Ceilão, nozmoscada Indonésia e cravo Malaio.

E o luxo da mesa romana não ficava apenas nos condimentos. A ostentação começava pelo lugar onde a alimentação seria servida: num ambiente com refinado mobiliário, tendo as paredes e o chão decorados com mosaicos e pinturas, por onde escravos bem vestidos desfilavam para apresentar pratos exóticos suntuosamente decorados em serviços de ouro, prata, cristal e vidro trabalhado. E os banquetes eram mais luxuosos quando seguiam a regra romana "mais que as Graças e menos que as Musas" - referiam-se ao número de convidados, nunca menos de três nem mais de nove (BUSTAMANTE, 2003, p. 107).

Um dos primeiros tratados específicos sobre gastronomia, inclusive, surgiu em Roma sendo escrito por Marcus Gávio Apicius (ou Apício, 25 a. C.), trata-se de "De re 
Coquinaria", ver em Apicius (2011). Apicius era pertencente à ordem dos eqüestres, sendo assim integrante direto da elite romana, sua fama e fortuna lhe trouxera a amizade de muitos membros da família imperial.

Apicius foi bastante criticado por alguns intelectuais de sua época que entendiam o seu interesse pela gastronomia como ócio (àquela época considerado prejudicial). Mesmo assim ele tratou de orientar jovens aristocratas na arte de cozinhar e dedicava grande parte do seu tempo a inventar ou a testar receitas, muitas das quais verdadeiras extravagâncias, como por exemplo, línguas de flamingo de rouxinol ou de pavão, cristas de aves vivas e calcanhares de camelos (PLÍNIO, 1961, 1991). Mesmo depois de sua morte, o nome Apicius ficou associado à culinária, tanto que Apicius permaneceu como expressão corrente para designar glutão ou cozinheiro (TERTULIANO, 2011).

Na obra "De re coquinaria Libri Decem", Apicius (2011) ressaltava o uso dos condimentos e, ao longo do seu texto, pode-se observar uma lista de temperos, os quais ele acreditava que não poderiam faltar numa casa: açafrão, pimenta, gengibre, cardamono, semente de papoula, semente de arruda, bagas, bagas do louro, as sementes de endro, amêndoas, a semente de erva-doce, a semente da Ligúria, as sementes de rúcula, sementes de coentro, cominho, erva-doce, salsa, as raízes da lasaris, hortelã, catmint, sálvia, cipreste, manjerona, zimbro, cebola, tomilho, coentro, citron, cebola de Ascalon, as raízes do junco, endro, alho. Dos fluidos: mel, um vinho de uva temperado. Dos frutos secos: Damasco, tâmaras, uvas, romãs.

A alimentação da grande população de baixa renda da antiga Roma acalmava sua fome com pratos à base de legumes e sopas de ervas (mesmo as ervas bravas) enquanto os frutos e as saladas, temperadas com ervas aromáticas, eram servidas nas mesas dos ricos. $\mathrm{E}$ a disparidade na alimentação entre ricos e pobres mudou ainda mais quando se aumentou o consumo de peixe fresco, carnes e de pão - sobretudos os preparados com ingredientes importados de outras terras para ostentar luxo durante os banquetes.

Outra ressalva de como o poder e uso do luxo gastronômico esteve presente na história do Império Romano vem do texto de Plínio, o Velho (1991): Naturalis Historia, tratando-se de um episodio que seria simples para os dias atuais, mas que para aqueles tempos era prova de riqueza e poderio: cientes da importância do sal para a alimentação os romanos formavam grande demanda para o consumo diário de sal, este sempre 
insuficiente para atender as necessidades da população. Assim, desde o reinado de Anco Marcio (640-616 a. C.) o governo romano garantia o sal, mesmo este sendo um produto caro, e até fazia distribuição dele gratuitamente para todo o território romano - com fins propagandistas para explicitar ao mundo a riqueza de Roma (PLÍNIO, 1991, p. 89).

O uso do vinho surgiu também na antiguidade. Inicialmente era utilizado apenas em ocasiões especiais. Valbelle (1990, p. 1100) e Bresciani (1998, p. 58) esclarecem que no Egito o vinho além de ser feito de uva, poderia ser produzido a partir de tâmaras (a bebida fermentada seremet), figos (este bastante alcoólico) e romãs (pensa-se que este seria designado de sciadeh). Os autores complementam mencionando que os egípcios consumiam grandes quantidades do vinho importado da Síria, e que este consumo era, essencialmente, realizado durante banquetes ou outras ocasiões festivas.

Foi na antiguidade da Grécia e Roma que o vinho se popularizou. Existia uma máxima que dizia: "que antes de Dionísio (Baco) havia dois mundos distintos: o mundo dos homens e o mundo dos deuses - quase impenetrável" (COSTA, 2009, p. 32). E o vinho aparecia como uma ponte para se ficar mais perto dos deuses - através das bebedeiras. A bebida ganhou tanto status que possuía eventos específicos onde era homenageada. Costa (2009, p. 30) ilustra o exato momento em que surgiram estas festividades mostrando que este fato ocorreu quando a capital grega perdeu "um pouco do seu brilho na arte". E assim, Roma introduziu o culto a Baco e suas bacanais.

O maior exemplo disso eram as famosas bacanais, festas que homenageavam a Dionísio ${ }^{2}$ [de Dio(s), céu, em Trácio, e Nysa, filho: o filho do céu], o deus do vinho, as quais Pisístrato, um governante da Atenas de 605-527 a.C., fora o responsável pela oficialização do culto a Dioniso na Grécia onde realizava procissões com a imagem em embarcações com rodas ${ }^{3}$ puxadas por sátiros ${ }^{4} \mathrm{e}$ com homens e mulheres nuas no seu interior. O cortejo seguia com uma multidão mascarada até o Lénaion (templo sagrado dedicado a Baco) onde culminava com a hierogamia (o casamento do deus com a pólis inteira em busca da fecundação). (COSTA, 2009, p. 29-30).

2 Foi com o nome de Baco que Dionísio entrou em Roma. Segundo o que reza a mitologia, Baco era filho do deus Zeus e da mortal Sêmele. Era considerado o deus do vinho e da folia, representava seu poder embriagador, suas influências benéficas e sociais. Promotor da civilização, legislador e amante da paz. Líber é seu nome latino e Dioniso é seu equivalente grego. Pela história que a mitologia conta, percebe-se porque Baco "influencia” nas festas de bebedeira. (COSTA, 2009, p. 29)

${ }^{3} \mathrm{O}$ referido meio de transporte era conhecido na época como carrum navalis, - o que daria alusão aos carros alegóricos do carnaval atual. Ibidem, p. 29.

${ }^{4}$ Eram entidades grego-romanas naturais que possuíam uma metade humana e outra metade com corpo de bode. Normalmente eram-lhes consagrados o pinho e a oliveira e apesar de serem divinos, não eram imortais. Ibidem, p. 29. 
Hoje em dia estas festas são entendidas, vulgarmente, como comemorações de reputação duvidosa, realizadas em ambientes de libertinagem onde eram oferecidos banquetes extravagantes no mesmo instante em que as bacantes praticavam orgias e cometiam todos os excessos com os populares convidados - estando todos inebriados, alucinados pelo vinho.

Muitas das histórias de personalidades mundiais foram escritas graças à presença de alimentos considerados de luxo (caviar, trufas, vinhos específicos e carnes exóticas), como pode ser observado em Sombart (1990): Cleópatra oferecia suntuosos festins para seduzir seus amores e paixões; Catarina II da Rússia conseguiu engravidar e dar um herdeiro a Pedro, o Grande depois de ter comido caviar; deve-se o nascimento de Henrique IV a um patê de trufas e o da filha de Napoleão Bonaparte a uma pintada com recheio também de trufas, regada a champanhe; Madame de Pompadour comia moleja dada pelo seu real amante como remédio contra a frigidez.

A gastronomia e a excentricidade do luxo à mesa estão bem representadas na literatura ocidental, onde é possível encontrar diversas referências sobre as delícias utilizadas em épocas diferentes. Através da literatura, tem-se como saber, por exemplo, que: Shakespeare (2008), na sua peça “Henrique IV', descreve seu Falstaff se deleitando com iguarias que poderiam ser encontradas na mesa dos ingleses, naquela época como: lagosta com espessa mostarda de Tewkesbury, ovos com manteiga e rábanos tenros de Chersey, leitõezinhos assados de São Bartolomeu, congro de Gravesend com ervilhas de Eton, cebola vermelha de Staine e açafrão de Espanha, capões de Upminster e Harrow e pastelão de veado de Derby e Darmoor, tudo bem regado com vinho das Canárias; ao longo da obra "Decameron", de Boccacio (2002) o autor explicita a forma como os religiosos demonstram os seus interesses eróticos através da comida; a preferência do Marques de Sade pela carne de pombos embora; a perdição de Lutero, nos banquetes, apesar do seu ascetismo.

O requinte da alimentação também já foi utilizado para conquistas amorosas, como se observa ao longo de escritos sobre Casanova (CASANOVA, 1956; CHILDS, 1992; KELLY, 2009), de onde se podem extrair, inicialmente, cinco regras básicas para a conquista através do luxo gastronômico: 1 - Para conquistar as loiras, ofereça verduras frescas, frutos do mar, peixes na manteiga, ovos, comidas adocicadas, cremosas, suaves queijos não muito picantes. Bebem os vinhos brancos e champanhe; 2 - As morenas 
adoram hortaliças de perfume intenso, embutidos apimentados, risotos, carne vermelha, ostras com limão, queijos fortes, doces recheados e chocolate. Gostam dos vinhos tintos, como o Bourgogne e o Bordeaux, e do champanhe; 3 - As ruivas escolhem alimentos requintados e leves, mas por outro lado o temperamento as aproxima do fogo. Tomam vinhos brancos secos, os Côtes du Rhône e os rosados. E champanhe, sempre champanhe; 4 - Receita para um bom desempenho sexual: um cesto de ovos, canela-daíndia, gengibre e vinho de Chipre; 5 - Para aguçar o apetite sexual: 12 ostras no café da manhã e outras 12 no almoço.

Evidencia-se a relação entre o turismo e gastronomia, de acordo com Flandrin e Montanari (1998 apud MASCARENHAS, 2005, p. 27) , “a partir de 1920, quando ocorre um movimento contrário à cozinha urbana das grandes cidades. Desde esta época, tida como uma culinária artificial e sem sabor, tenta-se valorizar e resgatar as culinárias regionais".

Nos anos 70 e 80 o turismo de luxo gastronômico, por exemplo, poderia significar uma refeição nos restaurantes de duas e três Estrelas Michelin ${ }^{6}$. Porém, na atualidade com a maior valorização da gastronomia enquanto elemento cultural intangível, associada por sua vez à valorização da atratividade, unicidade e especificidade dos destinos turísticos, degustar o luxo gastronômico é buscar muito mais experiências do que o simples ato de comer num restaurante estelar (RICHARDS, 2007).

Assim a história da humanidade está impregnada de relações diretas com a gastronomia e o luxo à mesa, desde a antiguidade egípcia, passando pela Grécia tendo seus costumes aderidos pelo Império Romano até a renascença e a épocas das revoluções podem-se observar desenvolvimentos nas maneiras de preparar, se alimentar e incrementar as refeições - o que acabou sofisticando os hábitos alimentares, e faz com que a gastronomia e a presença do luxo à mesa sejam integrantes da herança cultural dos povos.

\footnotetext{
${ }^{5}$ Flandrin, J., MONTANARI, M. (Dir.). A Humanização dos Comportamentos Alimentares. In: História da Alimentação. Dos Primórdios à Idade Média. V. I. Lisboa: Terramar, 1998.

${ }^{6}$ Refere-se ao Guia Michelin, um guia turístico publicado pela primeira vez em 1900 por André Michelin, com o objetivo de promover o turismo para o crescente mercado automobilístico.
} 


\begin{abstract}
A gastronomia, assim como a viagem, é um inimigo da rotina. É curiosa e tem um senso universal. Não fosse a curiosidade e uma necessidade básica nossa de experimentar, degustar, provar, descobrir, agregado à capacidade de nossos cinco sentidos, não teríamos hoje a riqueza e a arte da boa mesa. Uma viagem através deste universo é a satisfação de uma de nossas necessidades mais importantes. (SEGALA, 2003).
\end{abstract}

A alimentação veio sofrendo transformações ao longo dos anos e se tornando cada vez mais refinada. E a partir das observações desta evolução órgãos competentes que tratam da preservação da cultura (como o Instituto do Patrimônio Histórico e Artístico Nacional - IPHAN), identificando a necessidade de preservar e conservar o patrimônio gastronômico acabou incluindo a gastronomia dentre os bens imateriais do patrimônio cultural. Além do seu valor simbólico (distinto em cada região) e de se preocupar em proporcionar o máximo de prazer a quem come a gastronomia ainda pode dizer muito sobre o ser humano. Afinal, cozinhar é uma ação cultural que liga as pessoas sempre ao que foram, eram e serão e, também, com o que produzem, creem, projetam e sonham.

Produzir alimentos refinados com ingredientes de luxo e que causam desejo e geram status é o foco da gastronomia de luxo. Status, por sinal, era o que buscavam os viajantes do turismo de luxo, quando praticavam o Grand Tour, como se observa a seguir.

\title{
3 O LUXO NO TURISMO
}

Ao longo dos anos o turismo tem sido alvo de inúmeras pesquisas e estudos científicos realizados por diferentes áreas do conhecimento humano em função da sua capacidade de gerar desenvolvimento e transformação (ambiental, social, cultural etc.). Por se tratar de uma atividade das que mais cresce no âmbito global o turismo possui um poder econômico considerável e por isto, tem estimulado cada vez mais estudos sobre ele.

Muitos historiadores apresentam a Roma e Grécia antigas como sendo o berço das práticas do turismo. De acordo com Lipovetsky e Roux (2005, p. 60) foi ao longo dos séculos XVIII e XIX que se pode perceber um maior desenvolvimento da atividade. Nos referidos séculos a atividade turística se encontrava vinculada as elites, que 
motivadas pelo ganho de status e pela curiosidade procuravam desvendar outras terras e descobrir outras culturas. Este fato mostra a existência histórica da presença do luxo no turismo, por se tratar de uma atividade, naquela época, acessível apenas para pessoas das classes mais abastadas das sociedades - ou seja, uma minoria, mesmo em escala global.

De acordo com Salgueiro (2002, p. 291) o Grand Tour e o Petit Tour eram as formas conhecidas de se praticar o turismo da época (século XVII). No entanto o Grand Tour foi percebido como o meio de excelência para se descobrir os centros culturais e intelectuais Europeus; e as viagens eram entendidas não só como lazer, mas como o instrumento privilegiado de/para se educar uma pessoa.

Camargo (2002) afirma que o termo Grand Tour foi utilizado pela primeira vez em 1670, em "Voyage of Italy: or a complete journey through Italy" - publicação sob a autoria de Richard Lassels. Na época de tal publicação o Grand Tour já estava consolidado como um reforço cultural e pedagógico por meio de viagens - que poderiam ultrapassar dois anos - a que se submetiam os filhos da nobreza e aristocracias.

Salgueiro (2002, p. 292) explicita que, embora o roteiro pudesse ter variáveis formas de ser percorrido, inevitavelmente o núcleo central era a Itália, e Roma em particular, atual centro mundial de cultura e educação. E quem optasse por fazer o verdadeiro Grand Tour, deveria se envolver num roteiro que envolvia essencialmente, além de uma viagem a Paris, um circuito pelas principais cidades italianas - Roma, Veneza, Florença e Nápoles, nessa ordem de importância. Outras capitais e cidades européias poderiam ser incluídas a este "roteiro base" mediante interesses mais particulares ou por mero capricho dos viajantes.

Viajantes ingleses comentavam com frequiência, e normalmente de forma positiva, sobre a comida e a bebida encontradas em lugares como a Itália. Muitos desses viajantes participavam de um Grand Tour, que tinha como objetivo proporcionar aos britânicos bem-nascidos conhecimentos sobre a história e a cultura da Europa. Muitos eram atraídos por outras diversões proporcionadas pelas terras estrangeiras e vários destes viajantes mencionavam o vinho em seus relatos de viagem (PHILLIPS, 2003, p. 193).

O objetivo do Grand Tour de expandir o conhecimento sobre cultura e educação acabou gerando outro hábito elitizado e altamente em moda: a elaboração de um diário 
de viagem, se possível ilustrado, dos momentos experienciados durante a viagem (SALGUEIRO, 2002, p. 301).

A escrita destes diários obedecia a regras metodológicas e tinha seu ápice com a sua publicação, no retorno do viajante. Este fato possivelmente ampliava as formas do conhecimento sobre os distintos lugares visitados e acabava despertando o interesse dos leitores para novas viagens em busca de novos conhecimentos.

Outro fator importante era que a publicação dos diários só aumentava o status do autor. Por isso, Salgueiro (2002, p. 301) conclui que os autores destes diários procuravam sempre incluir textos mais elaborados quando passavam por lugares históricos, colocando citações da literatura clássica para estabelecer uma relação do que foi visto com o que foi lido - podendo confrontar ideias com isto.

Messmann (1974, p. 22-23) reforça esta ideia citando o caso de Joseph Addison, um dos primeiros ingleses célebres a fazer o Grand Tour e a publicar seu diário de viagem intitulado de "Remarks on the Several Parts of Italy" (1705) - tratava-se de observações sobre a Itália através dos olhos dos antigos poetas latinos, como Horácio.

Pode-se entender, portanto que o uso do Grand Tour tornou-se moda de luxo na atividade turística a partir do século XVII ele gerava status e fama para quem o praticava. Porém com o passar dos anos esse tipo de viagem então foi perdendo espaço com a massificação do turismo. Entretanto, o mercado do luxo continua existindo de forma mais velada - e não menos luxuoso. Tanto que fez surgir o turismo de luxo - que envolve viagens e estadias em empreendimentos de alto padrão (de qualidade e refinamento), que oferecem produtos e serviços sofisticados.

Atualmente no turismo o luxo segue com formas cada vez mais requintadas para atrair os mais abastados, conhecidos pela sigla de VIP (Very Important People). Para concretizar este fato o site Luxurylab (2011) relata uma recente atitude posta em prática por uma famosa cadeia hoteleira destinada ao mercado turístico de luxo que, para aumentar sua proximidade com seus clientes VIP's resolveu entrar no mundo das redes sociais.

Desde abril de 2011 o grupo Jumeirah, membro da Dubai Holding, estendeu sua maneira diferenciada de fazer reservas de quartos e restaurantes: os hóspedes e os comensais podem agora procurar hospedagem e reservar restaurantes Jumeirah em Dubai, Londres e Nova York por localização ou por preferência de cozinha, ver todos os 
detalhes do estabelecimento, reservar uma mesa ou uma unidade habitacional que lhe agrade mais, e ter uma experiência única utilizando para este fim a sua própria pagina do grupo no Facebook (JUMEIRAH, 2011).

As propriedades do Jumeirah Hotels \& Resorts, são consideradas pelo senso comum, como as mais luxuosas e inovadoras do mundo e detêm inúmeros prêmios internacionais no segmento de viagens e turismo.

A rede internacional de gerenciamento de hotéis de luxo, baseada em Dubai, abrange o internacionalmente renomado Burj Al Arab, o hotel mais luxuoso do mundo e reconhecido como símbolo de Dubai, os diversas vezes premiados Jumeirah Beach Hotel, Jumeirah Emirates Towers, Madinat Jumeirah e Jumeirah Zabeel Saray, em Dubai; Jumeirah Carlton Tower e Jumeirah Lowndes Hotel, em Londres; e Jumeirah Essex House, em Nova York (SILVA, 2011).

\section{A MODA GOURMET OU GOURMAND?}

Como se pôde observar anteriormente, a atividade turística gerou a moda do Grand Tour entre as famílias mais abastadas do século XVII. Modismos são as formas mais fáceis para se identificar o que o mercado do luxo esteja ofertando para os consumidores. Assim observa-se a existência da moda Gourmet entre os consumidores da gastronomia de luxo.

O termo gourmet, que pode ser utilizado tanto como nome ou como adjetivo, vem da palavra groumet, que, em francês arcaico significa o "servidor de vinho", está relacionado à bebida, designando, portanto, os apreciadores da boa bebida, sobretudo de vinhos. Já a palavra gourmand significa, em francês moderno, o apreciador da alta gastronomia.

Devido a popularização da palavra gourmet no mundo "americanizado" existe um preconceito em se intitular gourmant (gourmand), já que essa palavra lembra glutony, um dos pecados capitais: a gula. O correto, portanto, partindo da França, "berço da gastronomia refinada", seria o apreciador pela alta gastronomia ser considerado um gourmand. 
Geralmente o termo gourmet é utilizado para um produto (comida ou bebida) que esteja associado à ideia da haute cuisine - alta cozinha, evocando assim um ideal cultural, associado com as artes culinárias, que conferem status. É a partir desta concepção, por exemplo, que se adjetiva de gourmet vinhos ou restaurantes, quando estes são de alta qualidade e estão reservados a paladares mais avançados e a experiências gastronômicas mais elaboradas. Ser adjetivado de gourmet (ou gourmand) traz consequência para o bolso dos clientes: quase sempre os produtos, refeições ou bebidas gourmets são caras se comparados com os tradicionais - não gourmet.

De acordo com McGrath (2007) o termo gourmet pode também ser associado, mais raramente, a uma pessoa, quando se lhe quer atribuir a qualidade de possuir um paladar apurado, e que possua algum conhecimento ou entendimento avançado de culinária e gastronomia.

No mundo globalizado a moda da comida gourmet, observada nos empreendimentos de restauração, surge como um incentivo à promoção dos produtos regionais (estes, muitas vezes utilizados como produtos na cadeia do turismo). Tal fato deve-se, provavelmente, pela busca de novidade e requinte por meio dos consumidores que escolhem a comida gourmand.

É importante ressaltar que fenômeno gourmet tem servido como contraponto do movimento fast-food. Associados a moda gourmet encontram-se outros aspectos importantes: a seleção criteriosa dos ingredientes de uma refeição; o tempo - que deve ser suficiente para o consumidor apreciar-devidamente o que foi ingerido; o modo - as técnicas de como preparar um prato ou uma bebida; e, o aspecto do prato - a apresentação dos pratos chega a ser comparada a uma obra de arte, tendo até designers específicos para a finalização do que foi preparado.

\section{O TURISMO GOURMAND}

Para compreender o que vem a ser o turismo gourmand se faz necessário, porém o entendimento do significado de turismo gastronômico - segmento do mercado turístico onde se encontra o nicho gourmand. 
De acordo com Mitchell e Hall (2003) o turismo gastronômico é entendido como uma viagem para fora do lugar de residência, motivada pelo interesse de comer e beber. É o que Quan e Wang (2004, p. 298) denominam como "experiência de consumo de comida no turismo". E, geralmente, está associado com eventos, como: festivais gastronômicos ou enogastronômicos; visitas às vinícolas; visitas a produtores de alimentos (primários ou secundários); participação em eventos gastronômicos; visita a empreendimentos de restauração, bares e afins, onde ocorra a degustação de alimentos e bebidas - objetivo principal da viagem.

A partir destes pressupostos a Canadian Tourism Commission (2002, p. 2) complementa que o turismo gastronômico pode apresentar várias formas como a de uma escola de comida, festas de gastronomia tradicional, participação nas festas das vindimas (celebrações sobre cultura do vinho), visita a adegas regionais, rotas dos vinhos, rotas gastronômicas, entre outras. E ainda, mostra o conceito de "turismo de culinária" (culinary tourism) - que não se restringe à experiência de comer ou beber, e vai além, contemplando também atividades de cozinha e/ou de agroturismo desenvolvidas para os visitantes do turismo gastronômico.

O turismo gastronômico ainda é responsável por ações outras que fortalecem a atividade, como: investigar as tradições gastronômicas, publicar livros de gastronomia local, divulgar a gastronomia local através de marketing promocional, incentivar parcerias público-privadas que valorizam a gastronomia, dentre outras (CANADIAN TOURISM COMMISSION, 2002. p. 2).

Associar o deleite gastronômico com a possibilidade de conhecer outros lugares e culturas acabou resultando numa fórmula tão bem sucedida que deu origem a um novo segmento do mercado turístico gastronômico: o turismo gourmand - ou turismo de alta gastronomia.

É interessante como a atividade turística pode fortalecer seus destinos através da gastronomia. O Vale do Rio dos Sinos e as Serras Gaúchas Brasileiras, por exemplo, tornaram o café colonial conhecido no mundo todo com a integração de circuitos gastronômicos que servem as iguarias doces e salgadas produzidas pelos imigrantes europeus daquela região. $\mathrm{O}$ atrativo talvez se dê pelo fato dos pratos oferecidos no café colonial serem produzidos como antigamente - afinal, hoje em dia tudo se pode comprar tudo feito de modo industrializado e congelado. (COSTA, 2008). 
Não foi encontrada na literatura utilizada para este manuscrito nenhuma conceituação para definir o turismo gourmand. No entanto, através da bibliografia percebe-se a existência de uma demanda cada vez mais sofisticada, que busca refeições e bebidas requintadas e personalizadas durante a realização de viagens.

Assim, pode-se definir o turismo gourmand como o nicho turístico que agrega o luxo gastronômico mediante a motivação de viajar pelo prazer de degustar a alta gastronomia e se deleitar com bebidas cada vez mais especiais - aqui, a ênfase está na exclusividade: Esta distinção entre qualidade e exclusividade é significativa, pois revela a intenção oculta por trás da viagem com motivação gourmand: além de saciar desejos, tem que conferir status.

Deste modo tem-se como abranger neste conceito a importância da identidade gastronômica dos destinos turísticos - fator cultural que, muitas vezes, é relevante na escolha do lugar a ser visitado e pelo sucesso dos mesmos (FOX, 2007).

Vive-se numa sociedade pós-moderna onde a experiência de consumo apreende uma função fundamental na vida socioeconômica, que pode ser entendida como "Economia das Experiências" (PINE; GILMORE, 1999). Tal economia, se voltada para o turismo gourmand, será associada à experiência turístico-gastronômica que ganha destaque quando a atividade consegue enfatizar novas experiências a partir da animação, da degustação, da observação de outra cultura, da aprendizagem, da observação da estética, do prazer, que juntos estarão proporcionando uma experiência "inesquecivel".

Para demonstrar as variadas formas que o turismo gourmand pode configurar em diferentes lugares do mundo apresentam-se, abaixo, dois exemplos que explicitam a prática da atividade turístico-gastronômica com o foco gourmand.

O primeiro exemplo traz a notoriedade que ganhou a Vivel Pátesserie \& Café, empreendimento gastronômico dubaiense voltado para o mercado de luxo. Mediante a moda ou status que o senso comum conferiu ao local, acabou sendo incluído como lugar de visitação turística para o público gourmand que visita Dubai.

Enquanto o segundo exemplo, evidencia a utilização de um equipamento essencialmente turístico, os cruzeiros marítimos, especialmente os da empresa Silversea, que volta suas atividades para o atendimento da demanda gourmand. 


\subsection{VIVEL PÂTISSERIE \& CAFÉ}

De acordo com Marinho (2011) a Vivel Pâtisserie \& Café (VIVEL PATISSERIE, 2011) fundada em 1992, com sede em Dubai, é reconhecida como a pâtisserie da realeza, dos gourmets e dos hotéis de alto luxo presentes nos Emirados Árabes (De Burj Al Arab a The Address, ao todo são mais de 20 estabelecimentos), sendo um dos motivos gastronômicos que motiva muitos apaixonados pela arte culinária gourmet a conhecer Dubai. Não bastando isso, ainda serve como referência para aqueles visitantes que desejam apreciar os aromas e sabores característicos daquela região.

A Vivel é um empreendimento de controle familiar que possui sete lojas nos Emirados (quatro em Dubai, uma em Abu Dhabi e duas em Al Ain), uma na América do Norte (em Montreal) e, por meio de franchising, a marca está no Kuwait, no Bahrein e na Arábia Saudita - e ainda exporta para empórios do mundo todo.

Marinho (2011) ainda relata que o empreendimento surgiu da paixão por doces da fundadora Shahnaz Bagherzadeh, motivo que a levou a passar uma parte considerável de anos indo à fazenda de sua avó, no norte do Irã, para aprender todos os tipos de receitas tradicionais. Os mais de 200 itens do menu Vivel revelam a presença do luxo e a miscelânea de influências presenciadas em Dubai que fazem com que Shahnaz e sua equipe criem delicadas guloseimas com ingredientes de qualidade elevada, para atender ao exigente público da Vivel.

\subsection{CRUZEIROS GASTRONÔMICOS SILVERSEA}

Os cruzeiros marítimos são elementos presentes na atividade turística. São verdadeiros resorts flutuantes que oferecerem, pelo menos, cinco refeições diárias enquanto o participante da viagem ocupa seu tempo entre piscinas, academias de ginástica, cassinos, shows, cinemas, biblioteca, sala de leitura, internet, aulas de dança, lojas free shop, teatros e muitas outras opções que se possa imaginar.

Basicamente existem três tipos de cabines num navio de cruzeiro: as internas, as externas e as suítes. As internas não têm janelas e varanda; as externas geralmente têm o mesmo tamanho das internas, mas podem ter varanda, escotilha ou janela panorâmica. As suítes normalmente têm dois ou mais cômodos: sala de estar, quarto(s), varandas. 
Algumas possuem antessalas, dois andares, elevador privativo e serviço de mordomo (WEB LUXO, 2008).

Dispondo de ambiente sofisticado e pensando no mercado de luxo A Silversea, empresa de cruzeiros marítimos resolveu programar viagens segmentadas para os apreciadores de gastronomia.

Amantes da alta gastronomia ganham cruzeiro temático - é com este tema que o site Web Luxo (2008) inicia suas informações sobre os primeiros passos da linha de cruzeiros de luxo italiana Silversea com foco em cruzeiros temáticos de alta gastronomia, projeto executado pelos mares e oceanos deste planeta, onde o turista é convidado a experimentar, por exemplo, maravilhas gastronômicas preparadas com temperos brasileiros, aromas exóticos das especiarias do Oriente Médio e Leste Asiático, o gosto picante do México e os vinhos inspirados nos molhos de Bordeaux.

Este tipo de cruzeiro temático começou a ser realizado desde 2008 através de uma parceria da Viking com a rede hoteleira Relais \& Châteaux (WEB LUXO, 2008). $\mathrm{Na}$ mesma fonte consta que a Viking é um gigante empresarial renomado por ser fabricante de equipamentos para cozinhas de luxo e apreciadores de detalhes refinados da área gastronômica. Também que a empresa disponibiliza um quadro de Chefs renomados que interage diretamente com o passageiro durante a viagem. E que quando os Chefs da Viking não estão a bordo, os famosos internacionalmente Chefs da cadeia de hotéis Relais \& Châteaux são convidados para acompanhar os turistas na sua viagem gastronômica.

A Relais \& Châteaux, rede criada na França, em 1954, com a missão de disseminar a art de vivre, por todo mundo, selecionando propriedades e serviços com características únicas e exclusivas, possui uma privilegiada coleção de 500 do melhores e mais luxuosos hotéis e restaurantes gourmet, em 60 países; e reúne uma família de Chefs e proprietários de hotéis de todo o mundo (RELAIS E CHÂTEAUX, 2011).

Os programas de viagens enogastronômicas da Silversea contam com o Relais \& Châteaux L'Ecole des Chefs (TERROIR GOURMET, 2001) e o Culinary Arts Voyages, numa seleção excepcional de 14 cruzeiros temáticos. Com seus seis navios Silver Cloud, Silver Wind, Silver Shadow, Silver Whisper, o navio de expedição Prince Albert II e o mais novo da frota Silver Spirit -, a linha de cruzeiro Silversea é a única no mundo a manter restaurantes Relais \& Châteaux a bordo (WEB LUXO, 2008). Oferece 
ainda serviço personalizado de mordomo para todas as suítes. Durante a viagem, todas as refeições, gratificações, open bar com vinhos, champanhe e drinques estão incluídos no pacote.

Os programas da Silversea são distintos: no "Culinary Arts" os passageiros podem degustar e aprender os segredos de pratos assinados pelos melhores Chefs do mundo (WEB LUXO, 2008). Pois a brigada é composta por renomados Chefs que apresentam todo o seu talento durante jantares gourmet dinâmicos e informativos. Enquanto o Programa Relais \& Châteaux L'École des Chefs transforma o navio em uma escola de gastronomia em alto mar, e apresenta uma série de cursos e eventos executados por Chefs da bem-conceituada Escola de Culinária Le Cordon Bleu, de Londres, em parceria com Jacques Thorel, proprietário do L'Auberge Bretonne, na França, Grand Chef Relais \& Châteaux (TERROIR GOURMET, 2001).

Outro diferencial deste tipo de viagem é a opção dos “Jantares Gourmet" onde o instrutor acompanha um grupo a um restaurante ou hotel local, para explorar a culinária típica (WEB LUXO, 2008). Outra particularidade da junção entre as duas instituições de luxo, são as cartas de vinhos, feitas sob medida para os cinco restaurantes Wine Restaurant by Relais \& Châteaux, à bordo da linha Silversea (como por exemplo, o Le Champagne, a bordo dos navios Silver Wind, Silver Cloud, Silver Whisper, Silver Shaddow e Silver Spirit, que traz menus gastronômicos peculiares, especialmente preparados mediante a harmonização com vinhos Premium e sob a supervisão de um sommelier (TERROIR GOURMET, 2001). O Le Champagne possui uma taxa de US\$ 200 por pessoa incluindo a harmonização de vinhos e de US\$30 sem vinhos incluindo o curso completo de 4 pratos, sobremesa e degustação de cafés especiais (WEB LUXO, 2008). Uma particularidade é que os pratos são sempre escolhidos de acordo com os vinhos, e não o contrário.

\section{CONSIDERAÇÕES FINAIS}

Ao longo dos anos a alimentação vem sendo aprimorada e criando técnicas de refinamento e sofisticação para os alimentos. Isso fez surgir a gastronomia - mediante as 
diferenças culturais alimentares das nações. O simples fato de provar uma comida diferenciada já é por si só um elemento motivador.

Com este pressuposto a atividade turística incorporou uma segmentação especializada para atender ao turista que é motivado pelo desejo de comer e beber - o turismo gastronômico. No entanto, o aparecimento de uma demanda cada vez mais sofisticada e entendida na gastronomia gerou o turismo gourmand - com foco nas experiências da alta gastronomia, visando realização de desejos e obtenção de status.

Este fato prova de alguma forma, que a gastronomia tem um poder envolvente para atrair as pessoas (turistas ou não). Consecutivamente, o mercado turístico desenvolveu um segmento especializado para atender ao público gourmand e a partir desta ação foram surgindo empreendimentos, geração de empregos e renda, profissionais especializados, produtos diferenciados e visitantes mais sensíveis a novas experiências gastronômicas - sobretudo para o mercado de luxo.

A presença do luxo na humanidade serviu para dar valores às "coisas" e fazer o homem sentir-se realizado quando pode explicitar seu status (por meio do consumo do luxo). Por ser um produto cultural (assim como a gastronomia) o luxo está presente em todas as sociedades e se manifesta de forma diversificada.

O luxo está presente na gastronomia desde os tempos mais remotos. E foi através de viagens que os ingredientes de ostentação gastronômica passaram a ser cobiçados.

A presença do luxo na atividade turística foi de fato percebida com a presença do Grand Tour, quando as famílias abastadas enviavam seus filhos para fazer viagens de estudos em regiões diferentes das suas habituais. Durante essas viagens os estudantes se encontravam experienciando elementos culturais diversos, dentre estes estava presente também a gastronomia.

Propõe-se considerar que os alimentos de luxo são aqueles que oferecem um refinamento no gosto, na textura ou que possuam distinção na oferta, seja por sua quantidade (ingredientes raros ou de difíceis cultivos e produções) ou qualidade (sempre superior). Ou, ainda, por ser um ingrediente exótico - os alimentos exóticos, geralmente, são os ingredientes de luxo mais fáceis de ser identificados. 
Em termos gerais, compreende-se que os alimentos de luxo são desejáveis pelo simples fato de serem difíceis de obter. E que, geralmente, não são essenciais para a nutrição humana.

É exatamente o luxo dos alimentos que promove o turismo gourmand. Pode-se afirmar que o turismo gourmand começou a existir desde a antiguidade clássica, obviamente não com a forma atualmente conhecida, mas com ações que nos dias de hoje poderiam perfeitamente se enquadrar como tal. Este nicho do turismo é percebido quando se observam, através da história, pessoas influentes, conquistadores e curiosos que começaram a desvendar o mundo e a usar na sua alimentação os ingredientes de luxo encontrados em suas viagens de exploração (especiarias, ervas aromáticas, azeites etc.), e a desenvolver técnicas de cozinha, utensílios e outros objetos e artefatos, passando assim a fabricar alimentos refinados, com estética diferenciada que na maioria das vezes só eram servidos em festins, celebrações da nobreza e de ordem religiosa.

Os principais focos de ligação entre o luxo e a gastronomia para dar vida ao turismo gourmand são: a realização de desejos, através da satisfação gastronômica com alimentos de luxo, e o status.

Atualmente a globalização e a evolução dos meios de comunicação, talvez, possam ser consideradas como os maiores responsáveis pela divulgação dos feitos da gastronomia - sobretudo quanto ao uso dos ingredientes de alta qualidade (que possuem valor superior, tanto sentimental quanto financeiro). Com isso o mercado turístico resolveu observar o segmento gourmand, compreendeu as necessidades deste nicho e desenvolveu produtos e serviços para atender a esta demanda.

As possibilidades de trabalhar o turismo gourmand são inúmeras: desde rotas gastronômicas que levem os turistas a desvendar a alta gastronomia, ou mesmo a cozinha regional - com toques de chef e ingredientes exóticos; passando por visitas a empreendimentos gastronômicos considerados de luxo; desenvolver cruzeiros temáticos, que chegam a se transformar em escola de culinária, dentre outros.

Assim deve-se fortalecer a valorização gastronômica na atividade turística e incentivar estudos e pesquisas com foco gastronômico visando transmitir tanto para a população quanto para os profissionais da cadeia do turismo, e até mesmo para os turistas, a importância cultural da alimentação e de suas especialidades gastronômicas (patrimônio cultural imaterial). 
Cabe a atividade turística o planejamento de como usar a gastronomia gourmand como atrativo turístico, necessitando para este fim de uma organização adequada dos serviços de Alimentos e Bebidas (A\&B) que lidam diretamente com este tipo de nicho.

Os organismos responsáveis pela gestão da atividade turística devem atentar para as necessidades de se conhecer a gastronomia local e étnica para que no processo do planejamento turístico possam repensar formas para preservar a cultura gastronômica de um local. E depois, de alguma maneira, inseri-la no contexto gourmand. Esta ação poderia ser reforçada se as Instituições de Ensino que lidam com turismo e cultura fizessem o mesmo - ou fossem além, e instituíssem nas suas matrizes curriculares temáticas obrigatórias incluindo conteúdo gastronômico, pois nem todas assim o fazem.

A presença do nicho gourmand na atividade turística pode ser uma solução para os períodos de sazonalidade - se levar-se em conta que a necessidade de se alimentar não é sazonal; e, que se está tratando com um público de luxo, com motivação por comida e bebida diferenciada. Para o Brasil, a forma mais rápida de inserção no mercado do turismo gourmand seria a criação de festivais e rotas de alta gastronomia tendo como foco a vasta diversidade cultural gastronômica nacional.

Por fim, faz-se pertinente admitir que a gastronomia é um fenômeno que merece ser melhor estudado, sobretudo na área do turismo, por três motivos básicos: o homem não vive sem alimentos (sobretudo na condição de turista); deve-se preservar as tradições culturais gastronômicas brasileiras; e os estudos sobre os impactos da gastronomia na atividade turística podem servir como base para um planejamento mais adequado das ações propostas nos segmentos gastronômicos da atividade turística.

\section{REFERÊNCIAS}

AMIGUES, S.; THÉOPHRASTE. Recherches sur les Plantes. Paris, Belles Lettres, 1988.

ANDRÉ, J. L'alimentation et la cuisine à Rome. 2. ed. Paris: Les Belles Lettres,1981 [original de 1961].

APICIUS. Bibliotheca Augustana: De re Coquinaria Libri Decem. Mary Ella Milham's edition, nicely presented (Latin) [Texto on Line] Disponível em: <http://www.hs-augsburg.de/ harsch/Chronologia /Lspos t04/Apicius/api_excv.html >. Acesso em: 06/05/2011. 
L’art culinaire. trad. J. André. Paris: Les Belles Lettres, 1987.

L'arte culinaria. ed. G. Carazzali. Milano: Bompiani, 1990.

The Roman cookery of Apicius. London: Rider, 1988.

BERRY, C. J. The Idea of Luxury: A Conceptual and Historical Investigation. Cambridge: Cambridge University Press, 1994.

BLANC, N.; NERCESSIAN, A. La cuisine romaine antique. Grenoble, 1992.

BOCCACCIO, G. Decamerão. Trad. de Raul de Polillo. Belo Horizonte: Itatiaia, 2002.

BRESCIANI, E. Alimentos e Bebidas do Egipto Antigo. In: FlANDRIN, J.; MONTANARI, M. (Dir.). História da Alimentação. Dos Primórdios à Idade Média. Vol. I. Lisboa: Terramar, p. 53-62, 1998.

BUARQue DE HOLANDA, A. Novo Dicionário da Língua Portuguesa, Rio de Janeiro, Nova Fronteira, 1999.

BUSTAMANTE, R. M. C. Em torna da mesa da elite romana. In: Calíope: presença clássica. Programa de Pós-Graduação em Letras Clássicas Departamento de Letras Clássicas da Universidade Federal do Rio de Janeiro Rio de Janeiro, 11: 95-111, 2003.

CAMARGO, H. L. Patrimônio histórico e cultural. (Coleção ABC do Turismo). São Paulo: Aleph, 2002.

CANADIAN TOURISM COMMISSION. Acquiring a Taste for Cuisine Tourism: A Product Development Strategy, Canadian Tourism Commission, Ottawa. 2002.

CARNEIRO, H. Comida e sociedade: uma história da alimentação. Rio de Janeiro: Campus, 2003.

CASANOVA. G. G. Memórias. Editora Delta, São Paulo, 1956.

CASSON, L. Everyday Life in Ancient Egypt. Baltimore and London: The Johns Hopkins University Press, 2001.

CASTRO, I. O. O livro de cozinha de Apício: um breviário do gosto imperial. trad. I. de O. e Castro. Sintra: Colares Editora, 1997.

CHILDS, J. R. Casanova - Uma Nova Perspectiva. Editora L\&PM, Porto Alegre, 1992.

COSTA, E. R. C. Gastronomia: do cotidiano para o turismo. In: Educação Tecnológica: teoria e prática do turismo, da hospitalidade e do lazer. Mota e Aragão [Orgs.] Fortaleza-Ce. Expressão Gráfica e Editora, 2011. 
Gastronomia: uma sedução para o turismo. \{Artigo on Line Revista Virtual Partes, ISSN 1678-8419. Publicado em 20 de setembro de 2008. Disponível em: 〈http://www.partes.com.br/ turismo/ gastronomico/gastronomia01.asp>. Acesso em: 06/05/2011.

O Barão contando história I: O luxo do chocolate quente! [Artigo on line]. Publicado em 16 de setembro de 2010. Disponível em: $<$ http://confrariadobaraodegourmandise.blogspot.com/2010/09/o-barao-contandohistoria-i-o-luxo-do_16.html>. Acesso em: 06/05/2011.

Enoturismo: retomando o culto a Baco através do turismo. $\boldsymbol{e}$ Gesta Revista Eletrônica de Gestão de Negócios - ISSN 1809-0079. Mestrado em Gestão de Negócios - Universidade Católica de Santos/Facultade de Ciências Económicas e Empresariais - Universidade de Santiago de Compostela. eGesta, v. 5, n. 3, jul.set./2009, p. 27-38.

CIMMINO, F., El Hombre en la Vida Privada y Social. In: Vida Cotidiana de los Egípcios, Espanha, EDAF - Historia Bolsillo, 2002.

CURTIS, R. I. In Defense of Garum. The Classical Journal, V. 78. N. 3 (Fev.-Mar., 1983), p. 232-240; Published by The Classical Association the Midddle West and South. 1983.

DIODORO, S. Biblioteca Histórica, Libros IV-VIII, trad. de J. J. T. Esbarranch, Madrid, Editorial Gred, 1984.

DIOSCÓRIDES. De Materia Médica, translated by Lily Y. Beck. Publisher Hildesheim: Olms-Weidmann, 2000.

DOUGLAS, M. Decipering a meal. Daedalus, Winter 1972, p. 61.

FLANDRIN, J, MONTANARI, M. (Dir.). A Humanização dos Comportamentos Alimentares. In: História da Alimentação. Dos Primórdios à Idade Média. V. I. Lisboa: Terramar, 1998.

FOX, R. Reinventing the gastronomic identity of Croatian tourist destinations. International Journal of Hospitality Management, 26 (2007), p. 546-559.

FISCHLER, C. L'homnivore. Paris: Poche Odile Jacob, 2001.

GUIA DA SEMANA. O mercado de luxo brasileiro. Disponível em: <http://www.guiadasemana.com.Br/compras/noticia/o-mercado-de-luxo-brasileiro>. Acesso em: 06/10/2011.

JUMEIRAH. Disponível em: <http://www.jumeirah.com/Hotels-and-Resorts/> e na página do Facebook: <http://www.facebook.com/Jumeirah?sk=app _10617121 6118819>. Acesso em: 22/11/2011. 
KELLY, I. Casanova - Muito Além de um Grande Sedutor. Tradução de Roberto franco VALENTE. Rio de Janeiro. Jorge Zahar Editora, 2009.

LIPOVESTKY, G; ROUX, E. O Luxo Eterno - Da idade do sagrado ao tempo das marcas. Tradução: Maria Lúcia Machado. São Paulo: Cia. das Letras. 2005.

LUXURYBAM.COM. Grupo Jumeirah usa serviço diferenciado para aproximar seus clientes de luxo [Artigo on line]. Disponível em: <http://luxurylab.com.br/ 2011/05/02/grupo_jumeirah_usa_servico_diferenciado_para_aproximar_seus_clientes_ de_luxo/>. Acesso em: 20/08/2011.

MARINHO, M. Vivel, o sabor de Dubai. Artigo on line. Disponível em: <http://www.gestaodoluxo.com.br/gestao_luxo_novo/segmentos/alimentos/alimentos.as p>. Acesso em: 22/11/2011.

MASCARENHAS, R. G. T. A gastronomia tropeira na região dos campos gerais do Paraná: Potencialidades para o Turismo. Dissertação (Mestrado em Ciências Sociais Aplicadas), 169 folhas. Universidade Estadual de Ponta Grossa, Ponta Grossa-PR, 2005.

McGRATH, C. In: International HeraldTribune, publicado em 26 de janeiro de 2007. [Artigo on line]. Disponivel em <http://www.nytimes.com/2007/01/26/arts/26ihtauthor.4355835.html>. Acesso em: 06/05/2011.

MESSMANN, F. J.; Richard Payne Knight: The Twilight of Virtuosity. The Hague: Mouton and Co. N.V., 1974.

MITCHELL, R.; HALL, C. M. Consuming Tourists: food tourism consumer behaviour, In: Food Tourism Around the World. Development, Management and Markets, Hall, M. at al. (editors), Butterworth-Heinemann, Oxford, p. 60-80, 2003

PINE II, J, GILMORE, J., The Experience Economy, Harvard Business Scholl Press, Boston, 1999.

PLÍNIO, O VELHO (Gaius Plinius Secundus). Natural history. Trad. H. Rackam. Cambridge, MA: Harvard University Press, 1991. 10 vols.

. Pline l'Ancien. Histoire naturelle. Livre X. Texte établi, traduit et commenté par E. de Saint Denis. Paris: Belles Lettres, 1961.

PHILLIPS, R. Uma breve história do vinho. Rio de Janeiro: Record, 2003.

QUAN, S.; WANG, N. Towards a structural model of the tourist experience: an illustration from food experiences in tourism. Tourism Management 25, p. 297-305, 2004.

RELAIS \& CHÂTEAUX. Disponível em: <www.relaischateaux.com> Acesso em: 06/10/2011. 
RICHARDS, G. Cultural Tourism: Global and Local Perspectives. ATLAS, Greg Richards (ed.)/ATLAS, Haworth Press Inc., 2007.

SALGUEIRO, V. Grand Tour: uma contribuição à historia do viajar por prazer e por amor à cultura. Revista Brasileira de História. São Paulo, v. 22, 44, p. 289-310, 2002.

SAVARIN, B. A filosofia do gosto. Rio de Janeiro: Cia. Das Letras. 1995.

SEGALA, L. V. Gastronomia e Turismo Cultural. Revista Turismo - [Artigo on line] Disponível desde outubro de 2003 em: <http://www.revistaturismo.com.br /materias especiais/gastronomia.html>. Acesso em: 20/08/2011.

SHAKESPEARE, W. Henrique VI - $1^{\mathrm{a}}$. Parte. Tradução de Carlos Alberto Nunes (William Shakespeare - Teatro Completo em 3 vol. "Dramas históricos"). Agir, 2008.

2002.

Macbeth. Trad. Beatriz Viégas-Faria. Porto Alegre: L\&PM,

SILVA, F. Grand Hotel Via Veneto em Roma tem gerenciamento do grupo Jumeirah. Dubai, 05 Dezembro de 2011. Disponível em: <http://www.jumeirah.com/Global/Jumeirah\%20Group\%20Pages/Press/Press\%20Relea ses/Grand\%20Hotel\%20via\%20Veneto_\%20Portuguese.pdf>. Acesso em: 06/12/2011.

SOMBART, W. Amor, luxo e capitalismo. Lisboa, Bertrand Editora, 1990, p. 201.

TERROIR GOURMET. Silversea lança mais três Cruzeiros Gastronômicos Exclusivos com Relais \& Châteaux. Disponível desde 04/07/2011 em: <http://www.terroirgourmet.com/2011/07/silversea-lanca-mais-tres-cruzeiros.html>. Acesso em: 06/10/2011

TERTULIANO. Apologia Tradução de José Fernandes VIDAL \& Luiz Fernando Karps PASQUOTTO. [texto on line] Disponível em: <http://www.tertullian.org/brazilian /apologia.html>. Acesso em: 07/05/2011.

VAlBELlE, D. A vida no Antigo Egipto. Mem Martins: Publicações EuropaAmérica, 1990.

VIVEL PATISSERIE. Disponível em: <http://www.vivel.com/> Acesso em: 06/10/2011.

WEB LUXO. Amantes da alta gastronomia ganha cruzeiro temático. [Artigo on line] Disponível desde $2008 \mathrm{em}$ : <http://www.webluxo.com.br/menu/turismo/altagastronomia_cruzeiro_tematico.htm>. Acesso em: 06/10/2011.

Recebido em: 31-12-2011.

Aprovado em: 31-01-2012.

Turismo \& Sociedade. Curitiba, v. 5, n.1, p. 310-339, abril de 2012. 